\title{
O passado manifesto
}

The Manifest(ed) past

AZEVEDO, Beatriz. Antropofagia: palimpsesto selvagem. São Paulo: Cosac Naify, 2016. 240p.

\section{Mauro Franco Neto}

franconeto.m@hotmail.com

Doutorando em História - Bolsista Capes

Universidade Federal de Ouro Preto

Rua Bicame, 40A, Passagem de Mariana

35420-000 - Mariana - Minas Gerais

Brasil

Palavras-chave

Tempo histórico; Literatura brasileira; Historiografia.

Keywords

Historical time; Brazilian literature; Historiography. 
Se a obra de Oswald de Andrade parece amplamente celebrada no meio cultural e universitário brasileiro, talvez o mesmo não possa ser dito em relação a uma exploração efetiva no presente das potencialidades que subjazem ao pensamento oswaldiano. É este talvez o principal intento de Beatriz Azevedo no livro Antropofagia - palimpsesto selvagemao colocar em cena uma história mantida obs-cena, um tema tabu que atravessa a história das ideias no Brasil e que pode, ainda hoje, ser pensada enquanto um caminho reflexivo para o nosso tempo.

Em transcriação permanente, a antropofagia inspirou um conjunto de artistas e intelectuais, em especial após o tratamento conferido ao tema por Oswald Andrade ao longo da primeira metade do século passado: dos modernistas aos poetas concretos, do Teatro Oficina de Zé Celso às linhas de Oiticica e Lina Bo Bardi, do Cinema Novo à Tropicália. Esta resenha do livro de Beatriz Azevedo traz, porém, algumas provocações com um alvo preciso: em que medida o desdobramento da antropofagia oswaldiana enquanto caminho crítico hoje pode interpelar a historiografia? Ou ainda, será que sua potência reflexiva não traria à cena um conjunto de questões ainda não suficientemente desdobradas por historiadores, tais como a tênue fronteira entre passado, presente e futuro, a existência de outras formas de historicidade possíveis e uma forma particular de tematizar o passado que envolve o anacronismo enquanto condição existencial?

O livro de Beatriz Azevedo nasce do mestrado em Literatura Comparada defendido na USP em 2012. Ao longo de sua trajetória, porém, Beatriz Azevedo soube transitar por diversos outros espaços além da academia. Poeta, cantora e compositora, a multiartista atuou, dirigiu e foi premiada por diversas peças teatrais. Publicou ainda dois livros de poesia, Idade da Pedra (Iluminuras) e Peripatético (Iluminuras). Sempre esteve sob os seus olhos, porém, o tema da antropofagia, o qual discutiu em países como os Estados Unidos e a França, além de assinar a curadoria do Encontro Internacional de Antropofagia no Sesc Pompeia. ${ }^{1}$

Como um dos últimos livros publicados pela editora Cosac Naify, sua estrutura simula o banquete antropofágico propriamente. A entrada traça algumas linhas fundamentais da obra de Oswald como o início do interesse pela antropofagia nos seus primeiros escritos do início do século, a relação tensionada com o campo intelectual modernista, tanto nacional quanto internacional, em especial com as vanguardas artísticas, além das estreitas vinculações políticas que o próprio autor acaba por tomar na década de 1930. O primeiro prato traz detalhes da construção da Revista de Antropofagia que publica, de maneira inédita, o Manifesto Antropófago em 1928, além de destacar certos aspectos da estrutura formal do manifesto que aparecerão nesta resenha mais adiante. 0 prato principal traz, dente por dente, uma leitura dos cinquenta e um aforismos que compõem o Manifesto e esmiúçam os múltiplos sentidos e possibilidades do experimento oswaldiano. Reservada para o banquete e a sobremesa, fica uma

\footnotetext{
${ }_{1}$ Para uma visão completa da obra de Beatriz Azevedo com os principais detalhes biográficos, premiações, atuações, eventos que organizou e participou, dentre outros detalhes ver seu site pessoal: http://www. beatrizazevedo.com/.
} 
exploração da potência inerente à ação devoradora do antropófago perante as formas artísticas, a linguagem e a temporalidade, através de princípios como a inversão e a invenção.

É preciso destacar, no entanto, que é da forma "manifesto" que irão nascer as principais questões que compõem o trabalho de Beatriz Azevedo:

Explorando as possibilidades polissêmicas do título escolhido por Oswald de Andrade, pensemos agora em 'manifesto' no sentido de algo evidente, inegável, palpável - algo que se manifesta, que irrompe, que existe. Possivelmente indicando que o antropófago não pode mais se esconder nem ficar apenas latente, Oswald de Andrade escolheu para seu texto um título polissêmico: o manifesto (substantivo) é antropófago, e elemento manifesto (adjetivo, no sentido de indiscutível, declarado, patente), ou seja, declaradamente antropófago (AZEVEDO 2016, p. 61).

O "manifesto" tem, portanto, uma primeira dimensão - aquilo que pode se tornar visível pela tradução em palavras -, mas também uma segunda face observada por Azevedo, a saber, de algo que está ali, latente, oculto, encoberto. O ente oculto seria a entidade brasileira advinda da profundidade de nossos ancestrais ameríndios, encobertos pela colonização. Oswald almejava direcionar esse estado latente, que está presente, mas invisível, em ente manifesto. Mais ainda, estava em jogo a tarefa de um desrecalque, isto é, a revelação de um material psíquico reprimido por anos de colonização que precisaria se tornar manifesto: "Precisamos, menino, desvespuciar e descolombizara América e descabralizar o Brasil" (AZEVEDO 2016, p. 62).

A leitura aprofundada dos cinquenta e um aforismos que compõem o Manifesto promovida por Beatriz Azevedo não tem como marca o esgotamento ou apenas a historicização das proposições oswaldianas. Interessa-lhe, mais amplamente, desdobrar reflexivamente o que ali aparece de modo a sublinhar a presença intempestiva da antropofagia e observar, a partir dela, um conjunto de questões relacionadas à temporalidade, à estética, à forma do texto e o papel performativo da linguagem poética, além de lançar um olhar antropofágico ao recorrente tema da identidade que por muito tempo acompanhou o debate sobre a antropofagia. ${ }^{2}$

É ao não sufocar a reflexão de Oswald, acentuando desmedidamente os impasses dos gestos modernistas, que Beatriz Azevedo consegue expor, por exemplo, as complexas relações entre o arcaico e o moderno existentes na sua obra, na qual a redescoberta das concepções ameríndias não inviabiliza uma reinvenção das próprias relações com as modernas invenções da técnica. Antes, a potencializa. Num ato de devoração das novas formas de acesso à informação - como expressa um aforismo do Manifesto ${ }^{3}$ - "se Oswald estivesse vivo ele

\footnotetext{
2 Um dos estudos seminais sobre a obra de Oswald, e que já identificara esse longo raio de ação da antropofagia é o de Benedito Nunes. Ali, Nunes identifica que a palavra antropofagia pode ser, contemporaneamente, metáfora, diagnóstico e terapêutica. Como um engenho verbal ofensivo, a antropofagia era metáfora quando se remetia à cerimônia guerreira da imolação do inimigo pelos tupis, englobando tudo que devíamos repudiar. Era ainda um diagnóstico de uma sociedade traumatizada pela repressão colonizadora que the condicionou o crescimento. E uma terapêutica, afinal, como vocábulo reativo, a antropofagia era uma reação violenta e sistemática contra os mecanismos sociais e políticos da instância censora (cf. NUNES, 1978).

3 "Só me interessa o que não é meu. Lei do homem. Lei do antropófago" (cf. ANDRADE, 2016, p. 13).
} 
estaria ligado à cultura digital", ${ }^{4}$ afirmou Azevedo em entrevista do jornal Folha de São Paulo.

O experimento antropofágico pressupõe, de tal modo, uma ida, não um regresso ao arcaico. É o experimento de outra concepção de mundo, ou ainda, de tempo. Na Revista de Antropofagia, em 1928, lia-se: "A descida antropofágica não é uma revolução literária. Nem social. Nem política. Nem religiosa. Ela é tudo isso ao mesmo tempo" (apud AZEVEDO 2016, p. 79). Ou seja, uma revolução de outra ordem. Melhor, para usar as palavras que encontramos no Manifesto: "Queremos a revolução Caraíba. Maior que a Revolução Francesa" (ANDRADE 1978, p. 14) As revoluções ou projetos de futuro do mundo sóciohistórico ${ }^{5}$ não eram então suficientes para compreender a natureza da descida antropofágica. E Beatriz Azevedo esmiúça também os significados políticos de tal (im)posturaoswaldiana, situando-o na crítica aos extremismos, mas também ao liberalismo, todos devidamente ajustados às características homogeneizadoras do mundo moderno, configurando propriamente suas preocupações de uma ordem outra.

A antropofagia trazia no seu núcleo a reinvenção das relações com o passado. Nesse movimento, mais do que o "homem histórico" - do tempo escatológico e do progresso das civilizações - criado pela própria ciência ${ }^{6}$ da história, interessava o "homem não datado", figura espectral associada a um passado remoto que permanecia como um assombro aos impasses e paradoxos do mundo histórico, em particular através das "estruturas matriarcais desaparecidas". O não datado permitia o acesso a um passado outro, a um tempo outro, marcado por aquilo que Benedito Nunes chamou de compreensão "transversal" do processo histórico, ou no que Eduardo Sterzi nomeou como uma nova e mais complexa imaginação do tempo e da história, "em que o aprofundamento não se satisfaça com a apreensão trivial do influxo vertical do passado sobre o presente".7

\footnotetext{
${ }^{4}$ Cf. http://www1.folha.uol.com.br/ilustrada/2016/07/1793425-beatriz-azevedo-devora-o-manifesto-antropofago-em-novo-livro.shtml. Acesso em: 14/12/2017.

${ }^{5}$ Há um binômio importante na obra de Oswald, realçado pelo escritor em ensaios tardios dos anos 1950, entre um dado mundo sócio histórico e o mundo não datado, associados aqui, respectivamente, ao patriarcado e ao matriarcado. Assim, Matriarcado e patriarcado representam para o escritor dois hemisférios culturais tão radicalmente opostos que dividiriam a história, sendo este o mundo do homem civilizado, aquele do homem primitivo. O matriarcado, aqui associado ao modo primitivo, traria consigo algumas características - a cultura antropofágica que entende o mundo não como dominação, mas devoração; o mundo não datado; a ausência de classes ou do Estado; o filho de direito materno; a propriedade comum do solo, dentre outros que vão aparecendo esparsamente no interior da densa cadeia imagética criada por Oswald. Por outro lado, o patriarcado fundado numa verdadeira revolução que extingue o anterior momento matriarcal para, através do direito legislado, instaurar a obediência, a organização coercitiva do Estado - personificação do legal. Com ele emergem as formas jurídicas patriarcais por excelência, a saber, o direito paterno, a propriedade privada do solo e o Estado de classes. Soma-se a isso, agora, o homem civilizado, o mundo sóciohistórico e a cultura messiâni$\mathrm{ca}$, dependente de grandes sistemas explicativos que garantam para o futuro, em forma de promessa, aquilo que lhes foi usurpado no presente, anteriormente compreendido como devoração pelo universo antropofágico. ${ }^{6}$ Aparece ainda na obra de Oswald, com maiores detalhes em A crise da filosofia messiânica, a proposição de uma "ciência errática", uma ciência do vestígio errático, que tivesse como virtude tal valoração da falta e do erro - capaz de reconstruir esses extratos obliterados por certo movimento geral da história. Mais do que acreditar que da ciência viria a solução racional para todos os problemas da sociedade, Oswald parece mais próximo daquilo que, mais contemporaneamente, a filósofa Isabelle Stengers tem chamado de uma ciência capaz de participar de uma inteligência coletiva dos problemas. Uma ciência outra e que se reaproprie da imaginação necessária para se abrir a preocupações, saberes e objeções outras. Cf. http://climacom.mudancasclimaticas.net.br/?p=2965. Acesso em: 14/12/2017

7 Ver Sterzi (2011, p. 440). O próprio Sterzi já havia feito movimento similar ao associar esse impulso temporal da Antropofagia com o que Walter Benjamin designava imagem dialética. Nas palavras do filósofo alemão:
} 
Na formulação de Beatriz Azevedo a mesma equação temporal acontece nos seguintes termos: o bárbaro de Oswald não se fundamenta na perspectiva de passado, mas em um movimento em direção ao futuro (AZEVEDO 2016, p. 130). Mais objetivamente, Azevedo identifica que palavras primordialmente associadas ao passado arcaico, como "matriarcado" e "Pindorama", aparecem no Manifesto numa só formulação contemporânea, o matriarcado de Pindorama, que aponta para o futuro, signo de um tempo entendido enquanto devir, tempo das simultaneidades. Tempo do "bárbaro tecnizado" (AZEVEDO 2016, p. 173).

O passado, e também a memória, ou eram fontes de vida e de energia para a recriação, ou então seguiriam aquilo que Nietzsche já alertara sobre o mimado caminhante ocioso no jardim do saber e depois retomado por Benjamin na epígrafe da décima segunda tese sobre a história. Contra a memória tabu, enlatada e cadaverizada, Oswald, no quadragésimo quarto aforismo, pensava sua totemização e devoração pura: "contra a Memória fonte do costume. A experiência pessoal renovada." (ANDRADE 1978, p. 18)

Como uma partitura poética, e Azevedo evidencia bem isso, o Manifesto antropófago está para além de rígidas e intransponíveis interpretações filosóficas, históricas, políticas ou culturais. A bem dizer, são essas interpretações possíveis e bem-vindas, e o que de alguma forma é o que também se faz nessa resenha, com o detalhe, porém, de que tais leituras não percam uma outra dimensão e virtude do Manifesto que é estar para além de certo "representacionismo", na busca por uma direta evidência entre signo e sentido. Tomar a obra por inteiro, no caso do Manifesto Antropófago, significaria, portanto, entender sua própria encarnação estética, seu corpus poético. Nas palavras da autora: "é no corpo mesmo do Manifesto que Oswald pratica a sua teoria." (AZEVEDO 2016, p. 101, itálico da autora). A atenção à materialidade da comunicação torna possível observar mesmo os recursos rítmicos, mântricos de que se vale Oswald: "Roteiros. Roteiros. Roteiros. Roteiros. Roteiros. Roteiros. Roteiros." (ANDRADE 1978 , p. 15) São bordões e ecos que vão e voltam no decorrer do Manifesto e expõem sua preocupação com a forma, o performático e uma atuação no "concreto" do texto. Assim, quando lemos no décimo sexto aforismo do Manifesto que "o espírito recusa-se a conceber o espírito sem o corpo", Oswald reafima a centralidade do corpo em sua concepção de mundo antropofágica. Ou melhor, se as ideias "queimam gente nas praças públicas" (aforismo 45), contra elas "somos concretistas" (aforismo 45) e, de tal modo, Roteiros. Roteiros. Roteiros...

A investigação única e exclusiva do sentido, atentando-se apenas para a teoria que se defende deixaria escapar também como Oswald atua, escreve. De tal postura, demonstra Azevedo, derivam mais rimas que soluções. Sem, contudo, perder o mote da questão ou deixar de provocar a reflexão. Frases curtas como "Tupi, or not Tupi that is the question" colocam mais dúvidas do que conclusões, exaltando um pensar a partir de provocações, de tocar o tabu,

"A imagem dialética é uma imagem relampejante no agora da cognoscibilidade, o-que-foi (das Gewesene) é apanhado" (apud STERZI, 2011, p. 440). Esta imagem, como forma do objeto histórico, ainda teria a virtude de exibir uma genuína síntese. Ou mais, a imagem teria como característica fundamental ser um evento do presente, forma suprema de uma "presença pura", tal como a imagem dialética oswaldiana por excelência. 
de exceder o limite. Valeria a pena cobrar de Oswald precisão conceitual? Sob quais riscos e com quais perdas?

Numa imagem extremamente feliz, o historiador Eelco Runia (2006, p. 309-321) definiu que a realidade histórica não nos aparece na forma de passageiro pagante, mas sim clandestino. Ou seja, não valeria muito mais a pena apostar nas dimensões do real que não se nos apresentam tal qual a intenção representacional do historiador, mas sim pelas margens e a despeito dos seus desejos de representação de sentido? Ou melhor, que Oswald e o seu "largo conceito", sua forma particular de apropriação da história - imprecisa, célere -, não teriam algo importante a nos dizer sobre a potência da presença do passado para além das intenções da representação?

O mérito de Beatriz Azevedo está também em se dirigir a uma das questões mais caras ao pensamento histórico: o problema da identidade. Antes de tudo é preciso clarificar que o antropófago nunca é, mas sim um vir a ser incessante, devir, potência. Então quando Oswald afirma que "o que precisamos é nos identificar" (ANDRADE 1978, p. 153) não se trata de uma reificação da ideologia da brasilidade, chave a qual a antropofagia foi por vezes lida, perdendo assim seu ponto nevrálgico, a saber, o tema da alteridade, de um "outro" que, menos que reduzido à minha própria imagem, seja apropriado para transcriação do próprio "eu". Ou, para usar as palavras de Eduardo Viveiros de Castro no provocante prefácio ao livro: "transformar-se, por meio dele, transformar-se em um eu Outro. [...] Não um ver-se no outro, mas ver o outro em si" (VIVEIROS DE CASTRO 2016, p. 16). ${ }^{8}$

A antropofagia revela, somado tudo isso, uma aproximação direta com o passado e o legado da tradição. Beatriz Azevedo ressalta que, mesmo os temas sendo similares aos autores contemporâneos e predecessores a ele índios, Brasil, colonização, escravidão - o tratamento dado por Oswald segue um caminho único. Assim, muito além da criação de identidades estáticas do passado que mais aprisionam e imobilizam, tratava-se de pensar a diferença, colocar o outro em primeiro plano e a partir dele transfigurar-se. Ou ainda, mais que buscar uma síntese identitária, Oswald procurou investir, anarquicamente, nas contradições e descaminhos do legado histórico.

Abrir-se à relevância da provocação/reflexão oswaldiana no Manifesto sobre os fenômenos da historicidade significaria assim um desafio particular à historiografia. Consolidaria um novo estatuto marcado pela incorporação de outras formas e textos, além de dar a seriedade justa a esse "pensar sobre a historicidade" desde o Sul, com suas respectivas implicações, como o pensamento ameríndio, o pós-colonialismo e a própria antropofagia. Um movimento talvez similar àquele sugerido por Oswald no décimo aforismo do

\footnotetext{
8 Movimento semelhante fora notado também por Henrique Estrada Rodrigues, em particular a partir da leitura de um pequeno ensaio de Oswald intitulado Um aspectro antropofágico da cultura brasileira: o homem cordial (1950). Ali, Rodrigues explora uma releitura antropofágica do conceito de "homem cordial", mobilizado de início por Ribeiro Couto e Sergio Buarque de Holanda, no qual identifica que a cordialidade não seria apenas "algo impuro, cujo contato deveria ser interditado em proveito de padrões mais civilizados de conduta. Ao contrário [...], para Oswald o conceito de cordialidade também seria indício "de uma sociabilidade mais transigente e comunicativa, atravessada 'sentimento do outro, isto é, ver-se o outro em si, de constatar-se em si o desastre, a mortificação ou a alegria do outro'"' (RODRIGUES, 2014, p. 309-321).
} 
Manifesto, no qual oferece ao então renomado antropólogo francês Lucien LévyBruhl a mentalidade primitiva para ele estudar, ao que o próprio Lévy-Bruhl qualificava de "mentalidade pré-lógica". Ora, também a historiografia só teria a ganhar no momento em que decidisse se abrir ao "pensamento selvagem" mas não aquele que se opõe ao "pensamento ocidental" - sim aquele que evoca o pensamento em "estado selvagem", não domesticado e em toda sua potência.

\section{Referências bibliográficas}

ANDRADE, Oswald. Do Pau Brasil à Antropofagia e às outras Utopias. Rio de Janeiro: Civilização brasileira, 1978.

CASTRO, Eduardo viveiros de. Que temos nós com isso? In: AZEVEDO, Beatriz. Antropofagia: palimpsesto selvagem. São Paulo: Cosac Naify, 2016, p. 11-20.

RODRIGUES, Henrique Estrada. Uma história cordial: Oswald de Andrade leitor de Sergio Buarque de Holanda. In: CLOCLET, Ana Rosa; NICOLAZZI, Fernando; PEREIRA, Mateus (Org.). Contribuições à historiografia luso-brasileira. São Paulo: Hucitec, 2014, p. 309-321.

RUNIA, Eelco. Presence. History and Theory, v. 45, p. 1-29, 2006.

STERZI, Eduardo. Dialética da devoração e devoração da dialética. In: CASTRO ROCHA, J.C; RUFFINELLI, Jorge. Antropofagia hoje? São Paulo: E-realizações, 2011, p. 437-453. 